\title{
Net Energy Analysis must not compare apples and oranges
}

\author{
Marco Raugei \\ Faculty of Technology, Design and Environment \\ Oxford Brookes University, Wheatley Campus \\ Oxford OX33 1HX, UK \\ e-mail: marco.raugei@brookes.ac.uk
}

\begin{abstract}
Standfirst: Energy return on investment (EROI) is a critical measure of the comparative utility of different energy carriers including fossil fuels and renewables. However it must not be used to compare carriers that cannot be put to similar end-use. Additionally, combining carriers to arrive at estimates of 'average' or 'minimum' EROls can be problematic.
\end{abstract}

The global demand for primary energy in 2017 was 585 EJ, of which over $80 \%$ was provided by fossil fuels (oil, coal and natural gas), and this cumulative energy demand is projected to increase by almost $30 \%$ by the year $2040^{1}$. At the same time, fossil fuel combustion is responsible for significant greenhouse gas emissions leading to rapid climate change and resultant negative effects. The world is thus faced with the formidable double challenge of curbing its overall greenhouse gas emissions while ensuring the continued delivery of sufficient energy to allow our societies to function.

Net energy analysis (NEA), as the name implies, is specifically concerned with determining how much 'net' energy can be delivered to society in the form of a given energy carrier, after subtracting all the energy inputs which are required to support the supply chain of that same energy carrier ${ }^{2}$. Its conceptual origins may be traced back to the 'energy theory of value' advocated by the Technocracy movement in the 1920s in the United States, and which gained further traction in the cultural milieu of the first oil crisis in the early $1970 \mathrm{~s}^{3,4}$. Over the years, NEA has established itself as a valuable tool in assessing the net energy profitability of a range of energy supply chains, as well as in cautioning against any associated risks, such as those posed by the increasing energy required to extract fossil fuels from dwindling deposits $^{5,6}$, and the prospect of an impending 'net energy cliff' followed by rapidly diminishing availability of net energy ${ }^{7}$. There is also a growing effort to include NEA-derived metrics in 
analyses of the energy-economy nexus ${ }^{8}$. More specifically, bringing about a major future energy transition will inevitably require a significant energy investment up front, and depending on the specific technologies employed and the rate at which the transition is implemented, there may even be a risk of potentially running into temporary net energy 'debt', whereby more energy investment is required to support a newly deployed energy technology (or, in extreme cases, even the entire energy sector) in a given year than the total energy that the technology (or sector) is capable of delivering in that same year ${ }^{9}$.

\section{System boundaries}

The principal metric of NEA is the Energy Return On (Energy) Investment (EROI or EROEI) - sometimes also referred to as Net Energy Ratio $(N E R)^{6,10}$ - which is defined as the ratio of the energy delivered ('returned') by a process (or chain of processes) to the total energy invested in order to operate those same process(es). Historically, 'standard' EROI values ${ }^{11}$ $\left(E R O I_{s t}\right)$ were typically calculated for energy resources 'at point of extraction'. However, despite seeming methodologically consistent at face value, such practice limits the

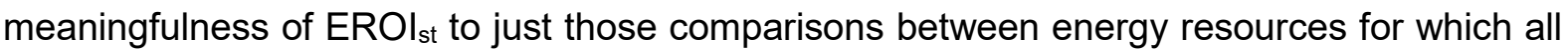
the subsequent process steps that are required to arrive at a usable energy carrier are essentially the same (as, for instance, when comparing crude oil produced in different fields or in different years $\left.{ }^{5,6}\right)$. In all other cases, energy resources can and do differ greatly in their actual usability at each stage of their respective supply chains. Broadly speaking, at one end of the spectrum are those primary energy resources which cannot be used directly as such in any significant societal application (e.g., crude oil and coal). In order to become usable energy carriers, these resources need to be refined, transported and so on, which ultimately leads to a reduced EROI 'at point of use' (EROI those primary energy resources which are instantly made available as readily usable energy carriers at their point of extraction (e.g., wind, photovoltaic and hydroelectricity); for these latter resources, the distinction between 'point of extraction' and 'point of use' therefore becomes more blurred.

It is noteworthy that the intrinsically different 'quality' of energy carriers such as electricity and thermal fuels has in fact been acknowledged in at least some of the literature to date. However, the ensuing issue about consistency in EROI comparisons has often been summarily addressed by simply adjusting the EROI of electricity upwards (or, correspondingly, that of thermal fuels downwards) using power plant conversion efficiencies $^{8,11,12}$. But recent detailed analyses ${ }^{13,14}$ have shown that this approach is too simplistic, since it fails to take into account the often significant additional energy 
investments that are required to refine and/or transport the fuels from their respective extraction points to the power plants.

\section{Oil and coal supply chains}

In the case of oil, life cycle inventory data ${ }^{15}$ indicates that the energy invested at the refinery $\left(I n v_{\text {ref }}\right)$ for the production of heavy fuel oil (HFO) is, on average, $4.5 \mathrm{MJ}$ (primary energy $) / \mathrm{kg}(\mathrm{HFO})$, which, when compared with the energy content of the fuel itself $\left(\mathrm{HHV}_{\mathrm{HFO}}=\right.$ $43 \mathrm{MJ} / \mathrm{kg}$ ), corresponds to over $10 \%$ thereof. In fact, such energy investment for refining is so large that, regardless of the exact amount of energy required to extract the crude oil from the ground ( $I n v_{\text {extr }}$ - which varies depending on the specific field and time frame considered, leading to a wide range of $\mathrm{EROI}_{\mathrm{st}}{ }^{7,11}$ - and even when considering the subsequent energy investments for transportation $\left(\operatorname{Inv}_{\mathrm{tr}}\right)$, it typically ends up being the input that most severely limits the maximum attainable $\mathrm{EROI}_{\text {pou }}=\mathrm{HHV} \mathrm{HFO} /\left(\operatorname{Inv}_{\text {extr }}+\operatorname{Inv}_{\text {ref }}+\operatorname{InV}_{\text {tr }}\right)$. This conclusion appears to hold for most oil-derived fuels (all of which tend to require very similar additional energy inputs for refining per unit of output), and is corroborated by several analyses using statistical data for the oil industry in various countries. Specific energy consumption data for the oil supply chain in Colombia in the year $2015^{16}$ have been reported as: Invextr $=39.4$ $M J / G J\left(\right.$ refined fuel), $I n v_{\text {ref }}=84.4 \mathrm{MJ} / G J\left(\right.$ refined fuel), and $I n v_{t r}=4.9 \mathrm{MJ} / G J($ refined fuel), which result in a significant drop from $\mathrm{EROI}_{\mathrm{st}}=25$ to $\mathrm{EROI}_{\mathrm{pou}}=8$. The situation is similar for the oil supply to Chile ${ }^{14}$, where $\mathrm{EROI}_{\mathrm{st}}=24$ and $\mathrm{EROI}_{\text {pou }}=6.2$. A review of the production of oil-derived fuels in North America ${ }^{17}$ reports an average refinery yield $\approx 0.9 \mathrm{MJ}$ (refined fuel) $/ \mathrm{MJ}$ (crude) and $\mathrm{Inv}_{\text {ref }}=600-1000 \mathrm{MJ} / \mathrm{bbl}$-crude, which corresponds to $0.1-0.18$ $\mathrm{MJ} / \mathrm{MJ}$ (refined fuel), thereby confirming this stage of the oil supply chain as the one requiring the most significant energy investment. Finally, historical data for California ${ }^{6}$ show that the $\mathrm{EROI}_{\text {pou }}$ of refinery products there has always been lower than 6.5 , even back in the $1950 \mathrm{~s}$ when the EROI st of crude oil at mine mouth was over 100. Hence, given that the EROI the oil-derived fuels that are actually used in all societal processes is fundamentally constrained by the refining step, rather than by the extraction of the crude from the ground, it also follows that it is much more informative and relevant to focus attention on the trend over time of such $\mathrm{EROI}_{\text {pou, }}$ than on the much steeper trend of the corresponding EROI $\mathrm{I}_{\text {st }}$ of crude oil at point of extraction (see Figure 1). 


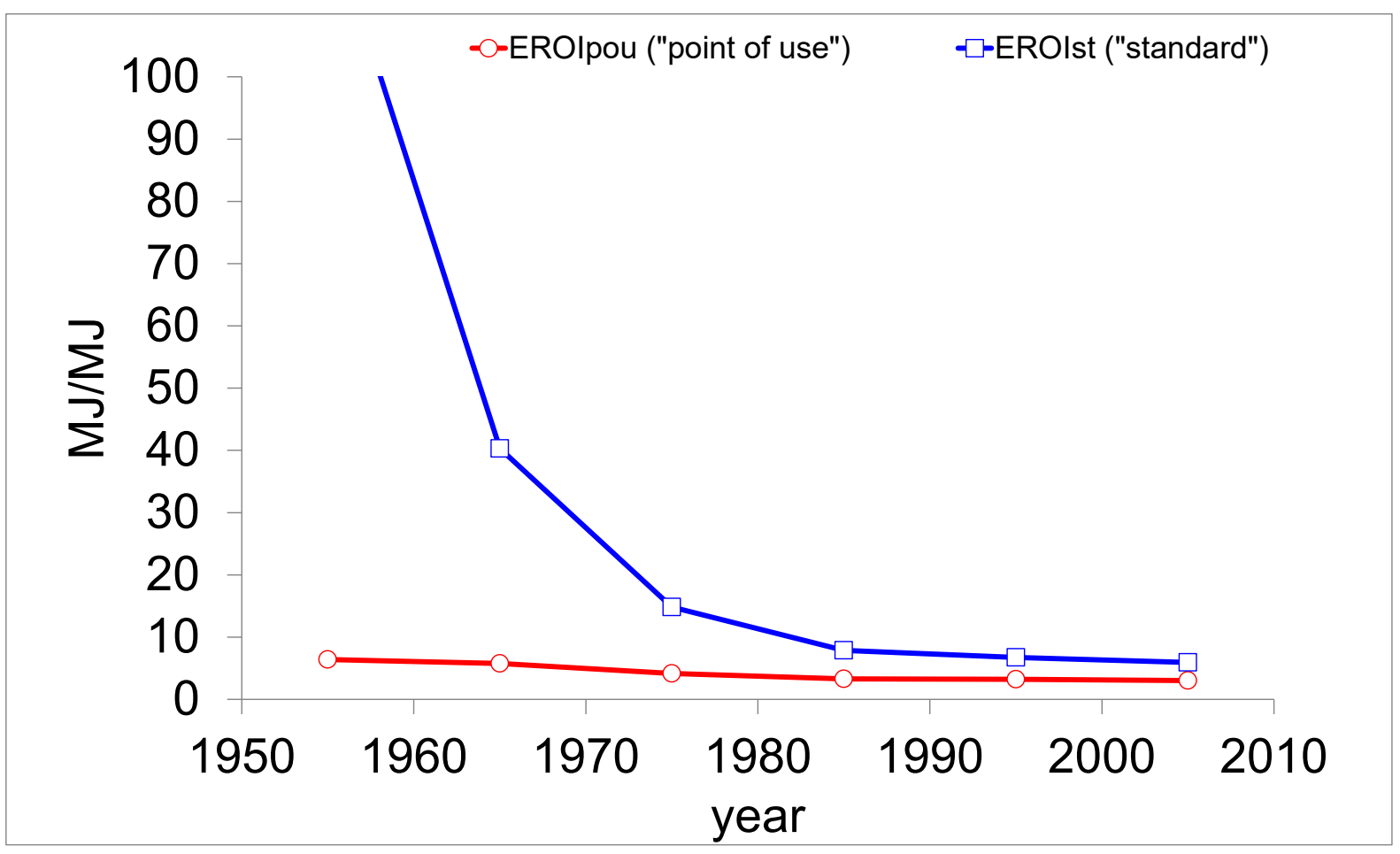

Figure 1. EROI of domestic oil supply in California. Historical trends of the $\mathrm{EROI}_{\mathrm{st}}$ of crude oil and of the corresponding EROI pou of refined oil fuels. Note the much 'flatter' curve of the latter. (data from Brandt ${ }^{6}$ ).

Moving on to oil-fired electricity, in principle, the additional energy investments to build and operate the thermal power plant should also be considered, but these tend to be negligible when amortized over the long service life of the plant and expressed per unit of electricity delivered ${ }^{15}$. As a result, the $\mathrm{EROI}_{\mathrm{el}}$ of oil-fired electricity may be calculated as: $\mathrm{EROI}_{\mathrm{el}}=$ $R^{*} E R O I_{\text {pou }}$, where $R=$ power plant efficiency. Given a typical $R=0.35^{18}$ and the range for $\mathrm{EROI}_{\text {pou }} \approx 6\left(\right.$ in Chile $\left.^{14}\right)-8$ (in Colombia ${ }^{16}$ ), the resulting $\mathrm{EROI}_{\mathrm{el}}$ is $\approx 2-3$, i.e., much lower than often incorrectly assumed by simply multiplying the $\mathrm{EROI}_{\mathrm{st}}$ of crude oil by $\mathrm{R}$.

Similarly significant reductions in EROI along the supply chain, from point of extraction to point of use, apply to many other thermal energy resources too, although the relative importance of the energy required for refining / processing (Inv $\mathrm{Iref})$ and for transportation $\left(\mathrm{Inv}_{\mathrm{tr}}\right)$ may be reversed. For instance, in three recent studies, the EROI of coal was found to be reduced from $27\left(\mathrm{EROI}_{\mathrm{st}}\right)$ to $11\left(\mathrm{EROI}_{\mathrm{pou}}\right)$ for the UK supply chain ${ }^{13}$, from $42\left(\mathrm{EROI}_{\mathrm{st}}\right)$ to 26 (EROI $\left._{\text {pou }}\right)$ for the Indonesian supply chain ${ }^{19}$, and from $65\left(\right.$ EROI $\left._{\text {st }}\right)$ to 20 (EROI $\left.{ }_{\text {pou }}\right)$ for the Chilean supply chain ${ }^{14}$. In all these cases, the main factor responsible for the reductions was Inv $_{\text {tr. }}$. Assuming an average $R=0.37^{18}$, such results then imply $E R O I_{\text {el }}=R^{*} E R O I_{\text {pou }}<4$ in the $\mathrm{UK}, \approx 7$ in Chile, and < 10 in Indonesia; once again, these are much lower values than has often been assumed using the oversimplistic formula $E R O I_{e l}=R^{*} E R O I_{s t}$. 


\section{EROI comparisons}

The take-home message in all this is that any comparisons among EROI values ensuing from different supply chains should always be taken with a grain of salt. As discussed above, even when the calculations are performed in a seemingly consistent way, i.e., by always referring to energy resources 'at point of extraction'7,20,21, the actual delivered energy carriers may still differ greatly in their direct usability (or otherwise), as they may have to undergo a wide range of subsequent processes (entailing additional energy losses and investments) before eventually being put to practical use. Instead, it would be recommendable for all comparative analyses to always ensure that the calculation boundaries are consistently extended to arrive at a common energy carrier delivered to the end user (e.g., a directly usable thermal fuel, or electricity), and that this is done not by means of simplistic assumptions or 'quality factors', but by duly accounting for all the necessary supply chain processes and the associated energy losses and investments. More specifically, when comparing conventional thermal vs. renewable electricity, this is in fact a 'bare minimum' requirement. Even more considerations may then come into play in determining the most appropriate basis for comparison, such as the need to address concerns about carbon emissions (which would, for instance, require carbon capture and sequestration to be implemented in the case of oil-, coal- and gas-fired electricity generation, with concomitant additional energy investments), or intermittency (which would require some degree of curtailment and/or energy storage in the case of renewable technologies such as wind or photovoltaics).

Finally, related issues arise whenever an overall 'average' EROI value is calculated for the whole set of energy resources used by a specific country (or even the whole world), and when the latter (or, for that matter, any individual EROI value) is benchmarked against a single postulated 'minimum' EROI that is supposedly required to support modern societies $^{7,11,21,22}$. Such estimations are problematic in two ways: firstly, as ought to be apparent based on what has been discussed here, 'average' EROI values are only methodologically sound and therefore ultimately meaningful if restricted to specific types of energy carriers (e.g., refined thermal fuels or electricity, but not a mix or the two, and most certainly not a mix of energy resources at point of extraction). In other words, both extraction and consumption boundaries must be reasonably assumed to be consistent across the board, and a common 'point of use' must be assumed, like for instance: a thermal engine, or an electrical motor. Secondly, comparing even consistently derived EROIs to any assumed 'minimum' value still implicitly rests on the assumption that the combination of 'downstream' process chains in which the energy carriers will be used in the future will remain essentially 
the same as they are today. In particular, the requirement for a relatively high 'minimum' overall EROI st has historically been due to the necessity to transport and refine (by means of additional energy investments) a mix of conventional fuels, before they are put to use in a range of unavoidably inefficient thermal processes, which are all ultimately limited by Carnot's principle. But when looking at the future, part of the appeal of a major energy transition (besides the environmental benefits in terms of reduced carbon emissions and pollution) is precisely to side-step such inherent supply chain and conversion efficiency limitations, essentially by pushing for more electrification in all sectors, while producing a large share of this electricity using low-carbon, renewable resources ${ }^{23}$. A significantly lower 'minimum' EROI may therefore well suffice to support such a fundamentally different future society relying on renewable electricity for a larger share of its energy metabolism.

Ultimately, therefore, we may conclude that the devil is always in the details, and that in order to be truly useful, all NEAs must be carried out at the appropriate system level, and within clearly defined and internally consistent spatial and temporal boundaries. Accordingly, there is a pressing need for the NEA community to work towards producing consistent EROI estimates 'at point of use' for a range of energy carriers ensuing from conventional and renewable supply chains, as well as for suitable mixtures of functionally equivalent energy carriers (e.g., blends of thermal fuels for transport, electricity grid mixes, etc.) in future scenarios. The inclusion of such estimates into overarching energy-economy models may then truly help to assess the foreseeable impacts and implications of the impending energy transition, including a potential major switch to renewables, and to identify any meaningful EROI 'minima' that may arise in each scenario and for each energy carrier.

\section{Competing interests}

The author declares no competing interests.

\section{References:}

1. World Energy Outlook (IEA, accessed on 13 December 2018); http://www.iea.org/weo/

2. Carbajales-Dale, M., Barnhart, C., Brandt, A.R., Benson, S.M. Nat Clim Change 4, 524527 (2014).

3. Discussion Paper No. 11, MIT-EL 81-065WP (Massachusetts Institute of Technology, accessed on 27 November 2018); http://dspace.mit.edu/bitstream/handle/1721.1/2023/SWP-1353-09057784.pdf 
4. Federal Nonnuclear Energy Research and Development Act of 1974 (United States Congress, accessed on 27 November 2018); https://bit.ly/2SfFhla

5. Cleveland, C.J. Ecol Econ 6(2), 139-162 (1992).

6. Brandt, A.R. Sustainability 3, 1833-1854 (2011).

7. Murphy, C., Hall, C.A.S. Ann NY Acad Sci 1185, 102-118 (2010).

8. King, L.C., van der Bergh J.C.J.M. Nat Energ 3, 334-340 (2018).

9. Carbajales-Dale, M., Barnhart, C., Benson, S.M. Energ Environ Sci 7, 1538-1544 (2014).

10. Kis, Z., Pandya N., Koppelaar, R.H.E.M. Energ Policy 120, 144-157 (2018).

11. Hall, C.A.S., Lambert, J.G., Balogh, S.B. Energ Policy 64, 141-152 (2014).

12. Raugei, M., Fullana-i-Palmer, P., Fthenakis, V. Energ Policy 45, 576-582 (2012).

13. Raugei, M., Leccisi, E. Energ Policy 90, 46-59 (2016).

14. Raugei, M., Leccisi, E., Fthenakis, V., Moragas, R.E., Simsek, Y. Energy 162, 659-668 (2018).

15. The Ecoinvent Database (Ecoinvent, accessed on 1 October 2018); https://www.ecoinvent.org/database/database.html

16. Yáñez, E., Ramírez, A., Uribe, A., Castillo, E., Faaij, A. J Clean Prod 176, 604-628 (2018).

17. Rahman, M.M., Canter, C., Kumar, A. Appl Energ 156, 159-173.

18. World Energy Balances (OECD/IEA, accessed on 1 October 2018); https://doi.org/10.1787/data-00512-en

19. Aguirre-Villegas, H. A., Benson, C.H. J Clean Prod 157, 47-56 (2017).

20. Hall, C.A.S., Day, J.W. Am Sci 97, 230-237 (2009).

21. Hall, C. A. S., Balogh, S., Murphy, D. J. R. Energies 2, 25-47 (2009).

22. Fizaine, F., Court, V. Energ Policy 95, 172-186 (2016).

23. Brown, T.W., Bischof-Niemz, T., Blok, K., Breyer, C., Lund, H., Mathiesen, B.V. Renew Sust Energ Rev 92, 834-847 (2018). 